\title{
A sexual evolution
}

Written in the flesh: a history of desire

Edward Shorter

Toronto: University of Toronto Press; 2005

298 pp \$29.95 (cloth) ISBN o-8020-3843-3

$\mathrm{H}$ aving written two books on the history of erotic language myself, I very much looked forward to reading medical historian Edward Shorter's latest offering, a history of sexual desire.

Sadly, the problem with this book begins with its title and bumps along with its premise. Here goes. The human brain is wired for what the author calls "total body sex." Not just the missionary position for men and women, "buggery" (as he calls it) for gay men or tribadism (genital rubbing) for lesbians. Every orifice, every inch of the human corpus is to be licked, touched, tickled, prodded and, for some over the last century, pinched or flagellated. Such hardwiring has been thwarted over time by a stifling lack of privacy in small villages and overcrowded huts, poor hygiene (smelly bits), disfiguring plagues (as from smallpox), the antilibidinal thrusts of Christianity, fears of pregnancy and its often lethal or maiming consequences, chronic pain (before the advent of Aspirin) and fleas and pests that induced fits of scratching quite inconsistent with carnal exploration. How do we know this? The author evades any scientific demonstration of what he presents as an almost evolutionary imperative by acknowledging that his thesis is decidedly Eurocentric. He then cites centuries'worth of written material describing the sexual behaviours of leaping lords and ladies, aristocrats, literary figures, horny curates, urban research subjects and the

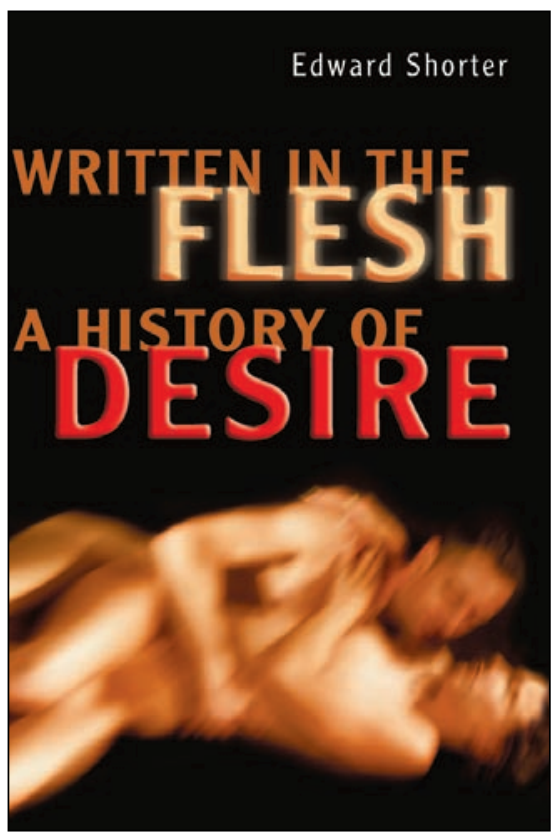

literate middle class. We glimpse the truth from pottery and paintings, too. Such excerpts are delightful to read and a major strength of the book. Shorter is often funny, and he is reassuringly fair to all orientations and genders. However, the book's emphasis on sexual practices fails to capture the essence of human desire. Desire exists in the mind (and, dare I say, the heart), and is not merely a thwarted neuronal drive sent to a skittish, inexperienced body.

Indeed, the word in this book's subtitle comes from the Latin desiderare, "to long for" or "to miss." One may desire, lust after, imagine, love, court and even stalk one's love interest and yet choose not to seduce, capture or ravage, whether socially obstructed or not. Longing is at least as significant and enduring a human striving as the slow but steady race to fellatio or cunnilingus. One can linger in a state of desire and deliciously tease one's neurons; after all, the brain is our biggest sexual organ. Read any poet from ancient to modern, and not just those quoted by Shorter to support his argument. Moreover, the book ignores the behavioural and evolutionary moulding of desire and coupling. There's no mention of Helen Fisher and how our concupiscence is reproductively driven and wins out over monogamy at least half the time. It does not explore how the gradual insistence of the women's movement on equal-opportunity orgasms has shaped recent sexual consciousness and activity. (The author refers to feminism's "deadening hand.") For a medical historian not to show us PET scans when generalizing about the erotic brain is almost unforgiveable. (What lights up in my limbic system may not light up in yours or anybody else's.) Finally, the book asserts that we are freer now than ever before without fully exploring the modern impediments or liberalizing influences that now dry up or lubricate modern sexual expression. HIV/AIDS is mentioned only in passing, and yet what better example is there in human history of the dangers of the erotic body? Pornography and the hardcore, home-based Web have opened our eyes to endless possibility and perversity. Many people just stay home.

So allow me to modify Shorter's title to Written on the Western Body: a Shockingly Selective but Highly Literary History of Specific Sexual Practices. More cumbersome, I'm afraid, but a tad more accurate.

\section{Allan Peterkin}

Department of Psychiatry

Mount Sinai Hospital

Toronto, Ont. 